\title{
Desenvolvimento e migração de larvas infectantes de ciatostomíneos (Nematoda: Cyathostominae) em gramínea coast cross (Cynodon dactylon) em clima tropical, na Baixada Fluminense, RJ, Brasil
}

\author{
Development and migration of cyathostome infective larvae (Nematoda: Cyathostominae) in \\ bermuda grass (Cynodon dactylon) in tropical climate, in Baixada Fluminense, RJ, Brazil

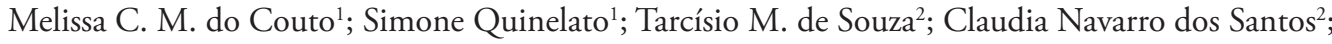 \\ Cláudia Maria L. Bevilaqua ; Débora H. da S. Anjos ${ }^{4}$; Ivan B. M. Sampaio ${ }^{5}$ Maria de Lurdes de A. Rodrigues ${ }^{6 *}$ \\ ${ }^{1}$ Curso de Pós-Graduação em Ciências Veterinárias - CPGCV, Universidade Federal Rural do Rio de Janeiro - UFRRJ e \\ Bolsista CAPES \\ ${ }^{2}$ Zootecnista, Autônomo \\ ${ }^{3}$ Departamento de Medicina Veterinária, Universidade Estadual do Ceará - UECE \\ ${ }^{4}$ Instituto de Biofísica Carlos Chagas Filho, Programa Biologia Celular e Parasitologia, Universidade Federal do Rio de Janeiro - UFRJ \\ ${ }^{5}$ Departamento de Zootecnia, Escola de Veterinária, Universidade Federal de Minas Gerais - UFMG \\ ${ }^{6}$ Departamento de Parasitologia Animal, Instituto de Veterinária, Universidade Federal Rural do Rio de Janeiro - UFRRJ
}

Recebido em 31 de Maio de 2008

Aceito em 27 de Fevereiro de 2009

\section{Resumo}

Esse estudo foi realizado no período de julho de 2003 a novembro de 2004, para avaliar o desenvolvimento, a sobrevivência, a migração das larvas infectantes em gramínea "coast cross" (Cynodon dactylon) e o horário de maior disponibilidade, em condiçóes de clima tropical, na Baixada Fluminense, RJ, Brasil. De julho de 2003 a setembro de 2004, massas fecais de equinos naturalmente infectados foram depositadas mensalmente sobre a gramínea. Sete dias após, amostras de fezes e gramínea foram coletadas semanalmente em diferentes horários (8, 13 e 17 horas), pesadas e processadas pela técnica de Baermann. O desenvolvimento, a sobrevivência e a migração das larvas infectantes nas fezes e na gramínea foram observados durante todo o período. A sobrevivência das $\mathrm{L}_{3}$ foi de até 15 semanas nas fezes e 12 semanas na gramínea no período seco e de nove e oito semanas, respectivamente, para o período chuvoso. No período chuvoso, maior número de $\mathrm{L}_{3}$ foi recuperado nas fezes e, no período seco, na gramínea. Condiçóes climáticas influenciaram diretamente o número larvas infectantes. Pela análise multivariada, ficou demonstrado uma forte relação entre o tempo e o número de $\mathrm{L}_{3}$ nas fezes, sendo esta relação menos acentuada para a gramínea. Não se observou diferença significativa entre os horários de coleta.

Palavras-chave: Cyathostominae, equinos, migração, coast cross, clima tropical.

\begin{abstract}
A study following the development and migration of Cyathostominae infective larvae was conducted from July 2003 to November 2004 in tropical climate, Baixada Fluminense, RJ, Brazil. Samples of naturally infected feces were placed on $12 \mathrm{~m}^{2}$ plot each month on a cyathostomin-free "Bermuda grass" pasture (Cynodon dactylon). After Seven days, samples of feces and grass were collected every week at 8 a.m, 1 and 5 p.m., weighed and processed by Baermann technique. Higher survival of $\mathrm{L}_{3}$ was found at dry season, 15 and 12 weeks on feces and sward respectively, at rainy season the survival was smaller. The multivariable analysis of main components was evident the influence of time and environment variables on $\mathrm{L}_{3}$ recovery from feces and grass. Close relationship between time and the number of $\mathrm{L}_{3}$ in feces could be noted, in contrast with $\mathrm{L}_{3}$ in sward. The climatic conditions influenced directly the number of infective larvae. The infective larvae were recovered during three times and the Kruskal-Wallis test did not present significance among them.
\end{abstract}

Keywords: Cyathostominae, horses, migration, bermuda grass, tropical climate.

\footnotetext{
*Autor para correspondência: Maria de Lurdes de A. Rodrigues

Departamento de Parasitologia Animal, Instituto de Veterinária,

Universidade Federal Rural do Rio de Janeiro - UFRRJ, BR $465 \mathrm{~km} 7$,

CEP 23890-000 Seropédica - RJ, Brasil; e-mail: lurdesar@ufrrj.br
} 


\section{Introdução}

Nematóides estrongilídeos são comuns e representam um grupo de grande importância. A maioria dos equinos apresenta infecção por nematóides da subfamília Cyathostominae com registros de animais parasitados, com mais de 1.200 .000 espécimes (ANJOS; RODRIGUES, 2003; 2006). O controle desses nematóides vêm sendo feito, ao longo das décadas, através do uso de anti-helmínticos, muitas vezes de maneira indiscriminada e sem estratégias de controle adequadas. Esse fato conduziu a resistência desses à maioria dos anti-helmínticos disponíveis, principalmente, aos benzimidazóis (KAPLAN, 2002; MATTHEWS et al., 2004). Dessa forma, é muito importante a utilização de métodos alternativos que limitem o uso de anti-helmínticos, como o controle das formas de vida livre na pastagem através da coleta manual de fezes ou métodos alternativos como a utilização de fungos nematófagos (HERD, 1986; LARSEN et al., 1995; RÉDUA et al., 2002; CASTRO et al., 2003). Estudos sobre o desenvolvimento e/ou sobrevivência de ovos e larvas de ciatostomíneos em pastagens vêm sendo desenvolvidos em zonas temperadas e em zonas tropicais (OGBOURNE, 1972; DUNCAN, 1974; CRAIG; BOWEN; LUDWIG, 1983; COURTNEY; ASQUITH, 1985; BAUDENA et al., 2000 a, b). Nesses estudos está evidente que a temperatura e a umidade sáo muito importantes para o desenvolvimento de ovos e larvas (RAMSEY et al., 2004).

Em estudos preliminares, observou-se que as larvas sobreviveram por até 12 semanas nas fezes e na pastagem (RODRIGUES, 1989) e que as fezes e a pastagem funcionam como reservatório e veículo de transmissão das $\mathrm{L}_{3}$. O solo também pode funcionar como reservatório em potencial, no entanto, as características e as condiçóes climáticas presentes podem afetar a viabilidade das larvas (HOUSTON; FINCHER; CRAIG, 1984).

A temperatura e a umidade influenciam diretamente o desenvolvimento das larvas infectantes, sendo necessária uma película de umidade sobre a vegetaçáo para migração das $\mathrm{L}_{3}$ (STROMBERG, 1997). Por esse motivo, pode-se sugerir que apenas a gramínea úmida represente risco de infecção para os equinos (LANGROVÁ et al., 2003). A gramínea coast cross (Cynodon dactylon) é amplamente difundida na produção de alimento para cavalos, pastagem ou feno, por isso é importante atentar para suas características morfológicas, avaliando sua influência na migração das larvas infectantes (VIANA, 1999). O objetivo desse estudo foi avaliar o desenvolvimento e a migração de larvas infectantes de ciatostomíneos em gramínea coast cross (C. dactylon), verificando o horário de maior recuperação e longevidade das larvas nas condiçôes de clima tropical da Baixada Fluminense, RJ, Brasil.

\section{Material e Métodos}

\section{Delineamento experimental}

O potencial de transmissão de larvas infectantes de ciatostomíneos em diferentes períodos do ano foi avaliado durante 17 meses, para estimar o desenvolvimento e a migração das larvas na gramínea coast cross. No período de julho de 2003 a setembro de 2004, massas fecais foram depositadas mensalmente e analisadas quanto ao número de larvas nas fezes e na gramínea. O número de ovos por grama de fezes (OPG) foi analisado a cada mês para se avaliar a variação durante o período. Amostras de gramínea e fezes foram coletadas em intervalos regulares (7 dias) para estimar o número de larvas infectantes por $\mathrm{kg}$ de matéria seca e para avaliar o período de sobrevivência de $\mathrm{L}_{3}$ nas fezes e na gramínea. $\mathrm{O}$ período de observaçôes foi de julho de 2003 a novembro de 2004.

\section{Local, canteiro experimental e animais}

O estudo foi realizado no Laboratório de Helmintologia da Estação para Pesquisas Parasitológicas W. O. Neitz do Departamento de Parasitologia Animal do Instituto de Veterinária da Universidade Federal Rural do Rio de Janeiro - UFRRJ, situado a $22^{\circ} 41^{\prime} \mathrm{S}$ e $43^{\circ} 41^{\prime} \mathrm{O}$, à altitude de $33 \mathrm{~m}$. Segundo Köppen, o clima é do tipo Aw (tropical chuvoso).

Foi formado um canteiro de coast cross (C. dactylon), com $12 \mathrm{~m}^{2}$, cercado por arame farpado e nunca utilizado para pastejo.

Foram utilizados equinos naturalmente infectados por nematóides estrongilídeos intestinais, como doadores de fezes. Durante todo o período do experimento, os animais não receberam nenhum tratamento anti-helmíntico.

\section{Procedimento e coleta de fezes e graminea}

As fezes foram coletadas diretamente da ampola retal do animal doador e analisadas quanto ao OPG através da técnica de Gordon e Whitlock (1939) para avaliação da carga parasitária. Larvas infectantes foram obtidas através de coproculturas de acordo com a técnica de Roberts e O'Sulivan (1950). As massas fecais foram depositadas, mensalmente, sobre a pastagem com uma distância de aproximadamente $50 \mathrm{~cm}$ entre elas. As $\mathrm{L}_{3}$ foram recuperadas pela técnica de Baermann (CORT et al., 1922), contadas sob microscópio e identificadas com base na chave de Bevilaqua, Rodrigues e Concordet (1993). Nos meses de março e agosto de 2004, devido a um incêndio, não foram realizados depósitos.

Sete dias após cada depósito, iniciaram-se as coletas semanais de fezes e gramínea nos horários de 8, 13 e 17 horas, retirando-se aproximadamente $2,0 \mathrm{~g}$ de fezes por amostra, atingindo todas as camadas da massa. As amostras de gramínea foram coletadas ao redor da massa, com uma distância de até $10 \mathrm{~cm}$ da mesma, foram pesadas e processadas pela técnica de Baermann. Após 24 horas no Baermann, $10 \mathrm{~mL}$ da suspensão de cada funil, foram coletados diretamente em tubo de ensaio. Para obtenção de matéria seca, as fezes e a gramínea foram levadas à estufa por 48 horas a $75^{\circ} \mathrm{C}$. As coletas foram encerradas após o esgotamento das $\mathrm{L}_{3}$ nas fezes e na gramínea.

\section{Dados meteorológicos e tratamento estatístico dos dados}

Os dados foram fornecidos pelo posto Agrometeorológico da Estação Ecológica Agrícola de Seropédica - INMET/ PESAGRO, RJ. 
Os dados de contagem de larvas nas fezes, na gramínea, período de sobrevivência, temperaturas médias do ar e do solo e precipitação total foram registrados semanalmente em planilhas.

Estatística descritiva dessas variáveis e sua variação sequencial no tempo foram calculadas e apresentadas em figuras para permitir a percepção da variação do número de larvas sob o efeito dos demais fatores. $\mathrm{O}$ efeito do horário de coleta sobre a disponibilidade de larvas na gramínea nos três horários estudados, foi obtido através da comparação dos valores médios utilizando o teste não paramétrico de Kruskal-Wallis (SAMPAIO, 1998; ZAR,1999), realizado pelo programa estatístico BioEstat (AYRES et al., 2005). $\mathrm{O}$ nível de significância adotado para os testes estatísticos foi de $\mathrm{P}<0,05$.

Para comparar as médias de OPG, sobrevivência e recuperação das larvas infectantes entre os períodos seco e chuvoso, foi utilizado o teste não paramétrico de Mann-Whitney (SAMPAIO, 1998; ZAR, 1999).

Para o estudo da dinâmica de migração de larvas para a gramínea, a frequência das larvas foi relativizada em relação à quantidade total obtida nas amostras de cada massa fecal durante o período de coleta. Esse procedimento corrige a variação encontrada entre os pesos de massas fecais e permitiu a apreciação de movimentação relativa no tempo, ainda que sob diferentes intervençóes (temperatura e precipitação).

Quando as coletas fezes e gramínea não apresentavam larvas, as observaçóes relativas àquela coleta não foram consideradas. Essa seleção prévia de dados eliminou as coletas iniciais e finais, onde as larvas estavam ausentes, isto foi realizado para eliminar a distorção do sistema algébrico, pois nesse caso, a ausência de resposta, os valores zero, não corresponde ao efeito causal de variáveis estudadas.

As coletas selecionadas $(\mathrm{n}=87)$ foram submetidas a análise multivariada de componentes principais (JUDEZ, 1989), englobando as seguintes variáveis: dias após deposição da massa fecal, temperaturas médias do ar e do solo, percentagem de larvas nas fezes e na forrageira e a precipitação pluviométrica da semana alvo.
A representação gráfica dessas variáveis no sistema tridimensional permitiu verificar em um sistema de coordenadas as associaçóes existentes entre elas.

\section{Resultados}

Os maiores valores da temperatura média foram observados durante o período chuvoso, em dezembro de $2003\left(25,9^{\circ} \mathrm{C}\right)$ e em janeiro de $2004\left(25,4^{\circ} \mathrm{C}\right)$. Os valores de temperatura média mensal e da precipitação total mensal estão apresentados na Figura 1. O maior valor registrado para índice pluviométrico correspondeu a novembro de 2003 (226,1 mm) e janeiro de 2004 (192 mm).

\section{Fezes}

O número de ovos por grama de fezes (OPG) variou durante todo período (Figura 2). O OPG médio foi de 2.858,3 $( \pm 1.351,4)$, amplitude 3.700 durante o período chuvoso (outubro a abril) e 2.342,9 $( \pm 1.088,4)$, amplitude 3.500 durante o período seco (maio a setembro). Foi observada diferença significativa entre os valores de OPG nos períodos seco e chuvoso.

A sobrevivência das $\mathrm{L}_{3}$ nas fezes variou durante todo o período do experimento. Maior sobrevivência das $\mathrm{L}_{3}$ foi observada durante o período seco, com permanência de até 13 semanas em 2003 e 15 semanas em 2004. No período chuvoso, as larvas infectantes sobreviveram no máximo nove semanas. Foi observada diferença significativa entre os períodos.

Nas fezes foram encontradas larvas infectantes durante todo o período do experimento, com picos nos meses de dezembro (M6 - chuvoso) e julho (M12 - seco), (Figura 3). O número médio de larvas infectantes nas fezes foi de $25.233 \mathrm{~L}_{3} \cdot \mathrm{kg}^{-1}$.MS no período chuvoso e $13.871 \mathrm{~L}_{3} \cdot \mathrm{kg}^{-1}$.MS no período seco, foi observada diferença significativa.

As larvas infectantes foram observadas durante todos os horários de coleta (8, 13 e 17 horas). No horário de 13 horas, observouse maior recuperação de larvas (com picos nos meses de julho e dezembro de 2003) quando comparado aos demais horários. Nos

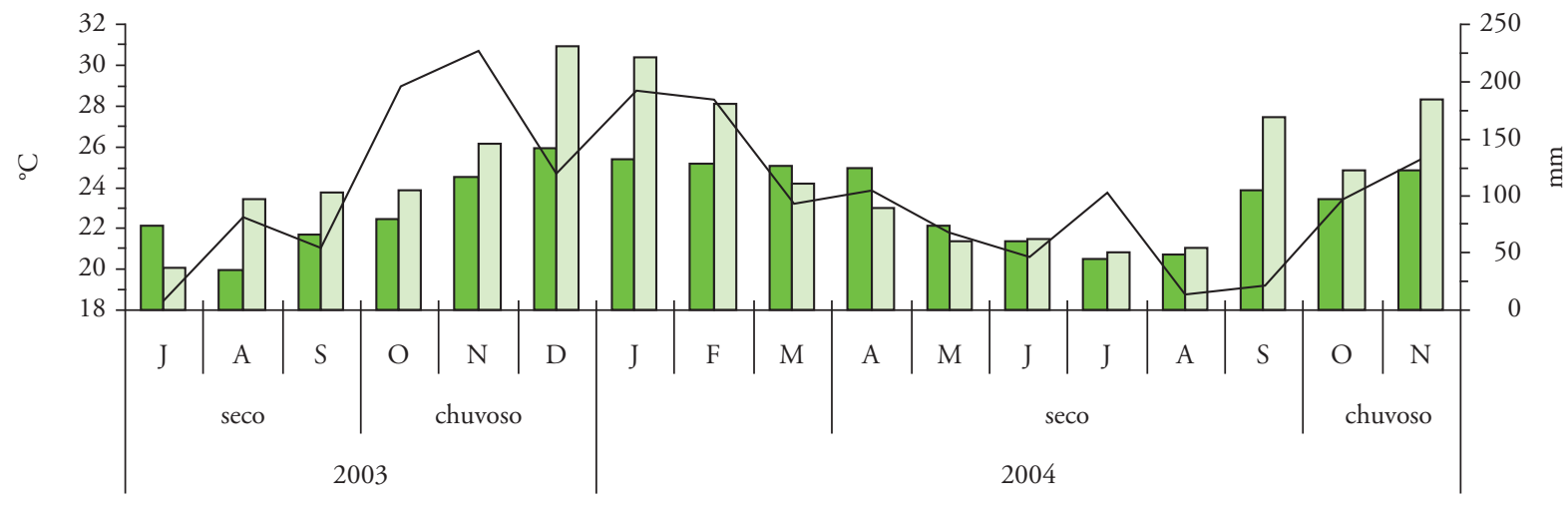

Meses

Temperatura do ar $\square$ Temperatura do solo — PPT

Figura 1. Temperatura média (ar e solo) e índice pluviométrico total no período de julho de 2003 a novembro de 2004. 
meses de novembro de 2003 e julho de 2004, observou-se maior recuperação de larvas infectantes às 8 horas quando comparado com os horários de 13 e 17 horas (Figura 4), não se observou diferença significativa entre os horários.

\section{Graminea}

O período de sobrevivência de larvas infectantes na gramínea coast cross variou de uma a 12 semanas. No período seco a sobrevivência foi de até 12 semanas e no chuvoso foi de até 8 semanas. A análise dos dados demonstrou diferença significativa entre os dois períodos.

Foram encontradas larvas infectantes na gramínea durante todo o período do experimento, com maior recuperaçáo de larvas nas massas M3 (Set. - seco), M7 (Jan. - chuvoso) e M11 (Jun. - seco) (Figura 5). No período seco, a temperatura média foi de $21,4^{\circ} \mathrm{C}$ e a precipitaçáo pluvial total de $501,8 \mathrm{~mm}$ e $843 \mathrm{~L}_{3} \cdot \mathrm{kg}^{-1}$.MS foram recuperadas. No período chuvoso a temperatura média foi de $24,6{ }^{\circ} \mathrm{C}$ e a precipitação pluvial total de $1.242,2 \mathrm{~mm}$ e $533 \mathrm{~L}_{3} \cdot \mathrm{kg}^{-1}$.MS foram recuperadas. Ocorreu variação na migraçáo entre os dois períodos, sendo que as $\mathrm{L}_{3}$, no período seco, migraram entre $1^{\mathrm{a}}$ e a $7^{\mathrm{a}}$ semana e no chuvoso entre a $1^{a}$ e a $4^{a}$ semana. Pela análise estatística foi observada diferença significativa entre os períodos.

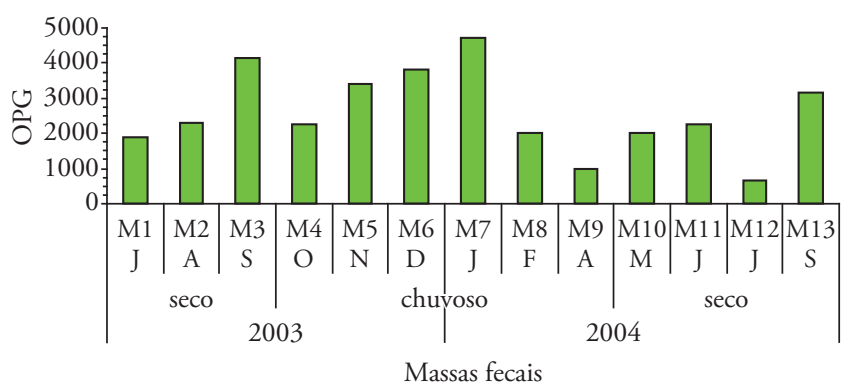

Figura 2. Número de ovos por grama de fezes (OPG) das massas fecais depositadas no período de julho de 2003 a setembro de 2004 .
Durante todos os horários de coleta, as $\mathrm{L}_{3}$ foram observadas na gramínea. No horário das 13 horas maior número $\mathrm{L}_{3}$ foi recuperado nos meses de agosto e setembro de 2003. No entanto, para o ano de 2004, maior recuperação de $\mathrm{L}_{3}$ foi observada no horário das 17 horas, com picos nos meses de janeiro e junho, exceto para o mês de setembro de 2004 quando ocorreu maior recuperação de $L_{3}$ às 8 horas, náo se observou diferença significativa entre os horários.

Para a análise multivariada, com a distribuição relativa de larvas nos substratos, as coletas selecionadas $(\mathrm{n}=87)$ estão apresentadas nas Tabelas 1 e 2.

A forte influência do tempo (dias) e das variáveis ambientais (temperatura e precipitação) sobre o número de $\mathrm{L}_{3}$ recuperadas nas fezes foram demonstradas pela análise multivariada, sendo essa relação menos acentuada para a gramínea. A redução das $\mathrm{L}_{3}$ nas fezes está diretamente relacionada com o aumento das $\mathrm{L}_{3}$ na gramínea (em função do tempo). Pouca variação ocorreu nos valores das temperaturas do ar e do solo, em conjunto com a precipitação, porém essas têm influência direta sobre a quantidade de $\mathrm{L}_{3}$ (Figura 6).

\section{Discussão}

\section{Fezes}

A proposta do presente estudo foi conhecer o desenvolvimento, migração e sobrevivência das larvas infectantes de ciatostomíneos das fezes para a pastagem coast cross.

No período chuvoso, que em clima tropical apresenta temperatura elevada, foram observados OPG mais altos, o que pode estar relacionado com a maior eliminação de ovos pelas fêmeas, pois as condiçôes climáticas são mais favoráveis, facilitando a migração das $\mathrm{L}_{3}$ da massa fecal para a gramínea. Nesse período a gramínea está mais palatável para os animais, aumentando a ingestấo de alimentos e consequentemente de $\mathrm{L}_{3}$. Em clima temperado, os maiores valores de OPG foram encontrados no

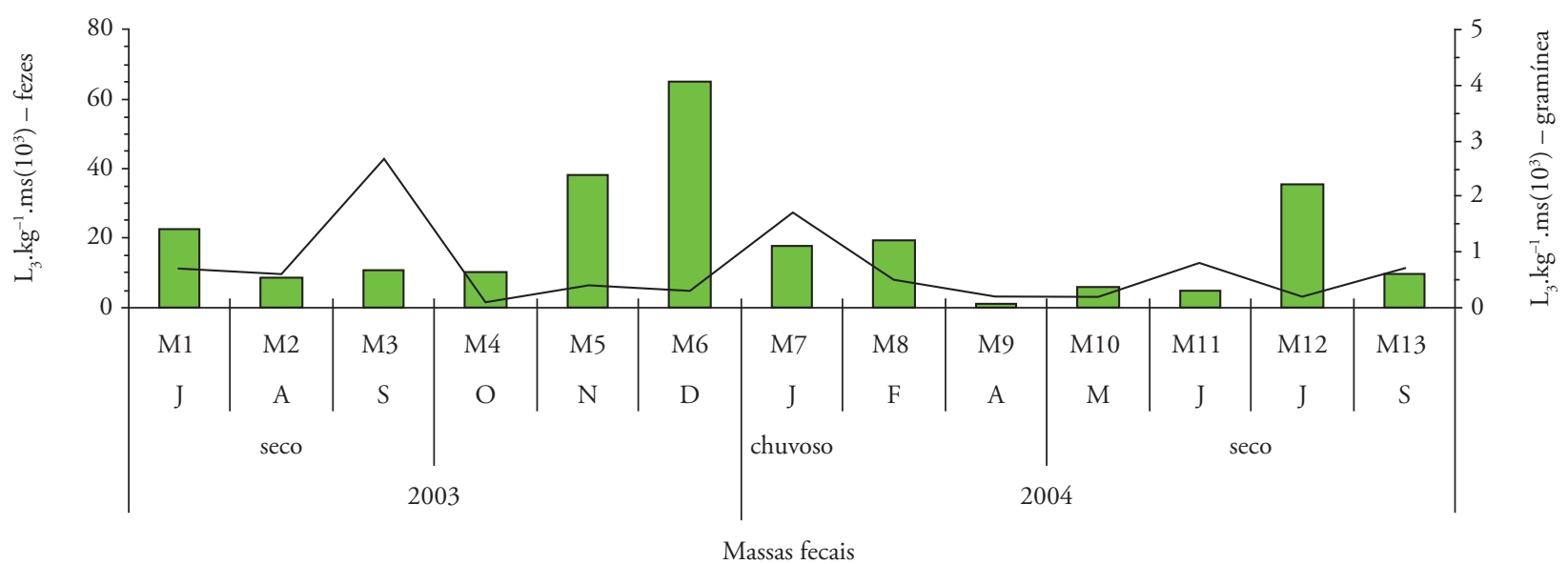

$\square$ Fezes — Gramínea

Figura 3. Número total de $\mathrm{L}_{3}$ recuperadas nas fezes e na gramínea no período de julho de 2003 a setembro de 2004. 


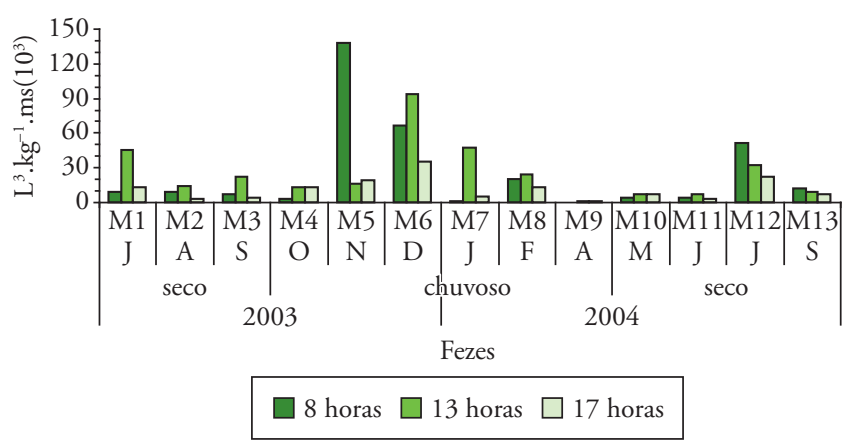

Figura 4. Recuperação de $\mathrm{L}_{3}$ de ciatostomíneos das fezes em diferentes horários de coleta.

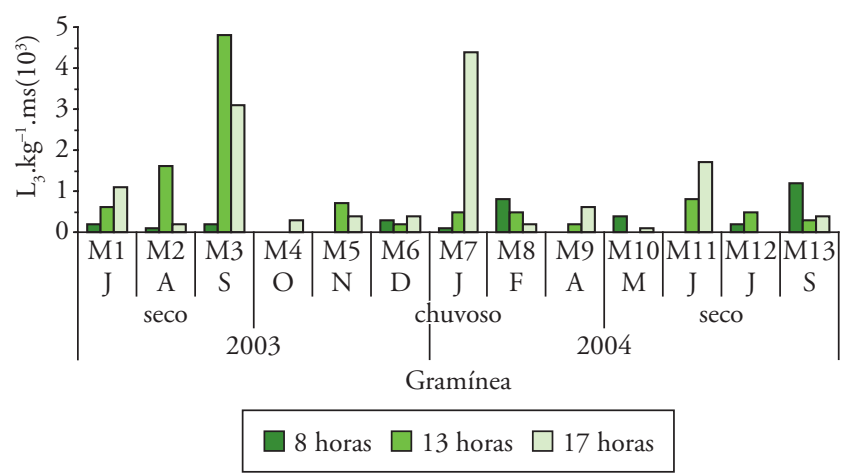

Figura 5. Recuperação de $\mathrm{L}_{3}$ de ciatostomíneos da gramínea em diferentes horários de coleta. final do verão e início do outono, onde existem condiçôes mais favoráveis para o desenvolvimento das $\mathrm{L}_{3}$ (COURTNEY, 1999; BAUDENA et al., 2000a).

No período chuvoso, as $\mathrm{L}_{3}$ sobreviveram por até 9 semanas $\left(18,2\right.$ a $\left.30,4^{\circ} \mathrm{C}\right)$, em temperatura considerada boa para o desenvolvimento, porém a variação desta acelera o metabolismo e o esgotamento das reservas das $\mathrm{L}_{3}$, diminuindo o tempo de sobrevivência. As temperaturas mais amenas no período seco $\left(16,3\right.$ a $\left.28,2^{\circ} \mathrm{C}\right)$ promoveram um aumento na sobrevivência das $\mathrm{L}_{3}$ (por até 15 semanas). A influência exercida pela temperatura também foi relatada por Courtney (1999) em condiçóes de clima subtropical úmido da Austrália, onde a sobrevivência das $\mathrm{L}_{3}$ durante o veráo é baixa, apesar de o desenvolvimento ser rápido e, no inverno o desenvolvimento é lento, porém a sobrevivência é alta.

A confirmação da variação sazonal no desenvolvimento das $\mathrm{L}_{3}$ de ciatostomíneos nas fezes em condições de clima tropical da Baixada Fluminense está evidenciada através desses resultados já descritos por Rodrigues (1989). Larvas infectantes foram encontradas a partir da primeira semana, com picos após 3 semanas, concordando com resultados obtidos em região de clima temperado (RAMSEY et al., 2004). Maior recuperação de $\mathrm{L}_{3}$ foi obtida no período chuvoso, na região estudada, destacando a importância desses fatores agindo em conjunto sobre a disponibilidade das larvas.

No presente estudo, a hora do dia não está significativamente associada ao número de $\mathrm{L}_{3}$ recuperadas, porém observou-se que às 13 horas o número de $\mathrm{L}_{3}$ recuperadas é alto quando comparado ao horário das 8 horas.

Tabela 1. Estatística descritiva das variáveis temporais, climáticas e frequência relativa de larvas.

\begin{tabular}{|c|c|c|c|c|c|}
\hline Variável & $\mathbf{n}^{\mathbf{a}}$ & Média & $s^{b}$ & Mínimo & Máximo \\
\hline Temperatura média & 87 & 23,29 & 2,26 & 17,80 & 28,10 \\
\hline Temperatura do solo & 87 & 25,19 & 4,14 & 20,00 & 36,70 \\
\hline Precipitação total & 87 & 26,31 & 30,93 & 0,00 & 116,90 \\
\hline$\% \mathrm{~L}_{3} \cdot \mathrm{g}^{-1}$ fezes & 87 & 0,11 & 0,15 & 0,00 & 0,89 \\
\hline$\% \mathrm{~L}_{3} \cdot \mathrm{g}^{-1}$ gramínea & 87 & 0,01 & 0,05 & 0,00 & 0,36 \\
\hline Dias & 87 & 38,46 & 22,44 & 7,00 & 91,00 \\
\hline
\end{tabular}

$\mathrm{n}^{\mathrm{a}}=$ número de amostras analisadas. $\mathrm{s}^{\mathrm{b}}=$ desvio padrão.

Tabela 2. Matriz de correlação entre as variáveis consideradas $(\mathrm{n}=87)$.

\begin{tabular}{|c|c|c|c|c|c|c|}
\hline & $\begin{array}{c}\text { Temperatura } \\
\text { média }\end{array}$ & $\begin{array}{c}\text { Temperatura } \\
\text { solo }\end{array}$ & $\begin{array}{c}\% \mathrm{~L}_{3} \cdot \mathrm{g}^{-1} \\
\text { fezes }\end{array}$ & $\begin{array}{c}\% \mathrm{~L}_{3} \cdot \mathrm{g}^{-1} \\
\text { gramínea }\end{array}$ & Dias & PPT total \\
\hline Temperatura média & 1,00 & - & - & - & - & - \\
\hline Temperatura solo & 0,71 & 1,00 & - & - & - & - \\
\hline$\% \mathrm{~L}_{3} \cdot \mathrm{g}^{-1}$ fezes & 0,16 & 0,13 & 1,00 & - & - & - \\
\hline$\% \mathrm{~L}_{3} \cdot \mathrm{g}^{-1}$ gramínea & $-0,14$ & $-0,15$ & 0,01 & 1,00 & - & - \\
\hline Dias & 0,06 & $-0,02$ & $-0,30$ & $-0,11$ & 1,00 & - \\
\hline Precipitação total & 0,16 & 0,12 & $-4,3 \mathrm{E}-03$ & 0,08 & 0,05 & 1,00 \\
\hline
\end{tabular}




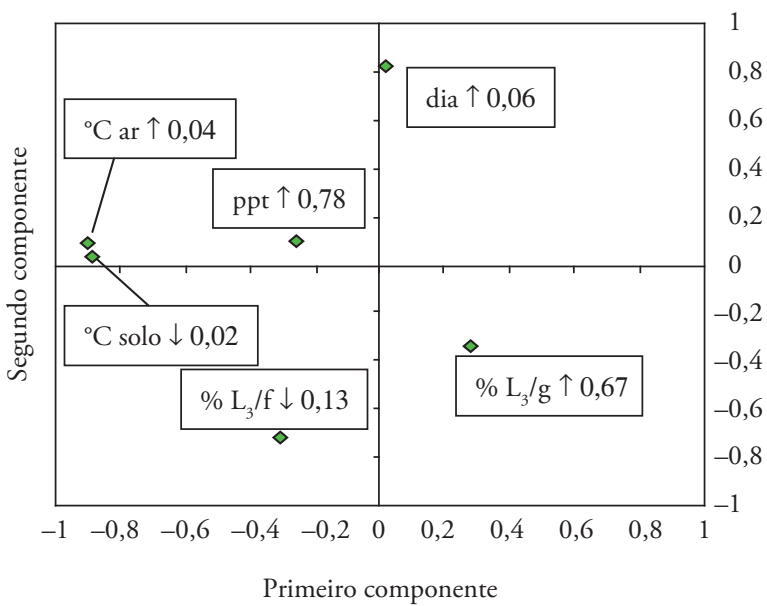

Figura 6. Representação gráfica das variáveis estudadas no sistema tridimensional originado pelos 3 primeiros eixos (componentes) principais, com inércia acumulada de $71 \%$, para gramínea coast cross (direção e coordenadas do $3^{\circ}$ eixo representadas pela direção da seta).${ }^{\circ} \mathrm{C}$ ar = temperatura do ar; ${ }^{\circ} \mathrm{C}$ solo = temperatura do solo; $\mathrm{PPT}=$ precipitação; dia $=$ tempo; $\% \mathrm{~L}_{3} \cdot \mathrm{g}^{-1}=\%$ larvas na gramínea; $\% \mathrm{~L}_{3} \cdot \mathrm{f}^{-1}=\%$ larvas nas fezes.

\section{Graminea}

O maior tempo de sobrevivência das $\mathrm{L}_{3}$ no período seco sugere que a disponibilidade das larvas na pastagem está diretamente relacionada às condiçôes climáticas. Estudos realizados em regiáo subtropical úmida da Austrália relataram a influência das variáveis climáticas sobre a sobrevivência das $\mathrm{L}_{3}$ na pastagem, onde durante o verão quente e longo a persistência foi menor do que nos meses mais frios (COURTNEY, 1999).

A presença das $\mathrm{L}_{3}$ foi observada durante todo o período do experimento. A maior recuperaçáo de larvas ocorreu no período seco quando a temperatura média foi de $21,4^{\circ} \mathrm{C}$, ideal para o desenvolvimento das $\mathrm{L}_{3}$ dentro da faixa de $19-24{ }^{\circ} \mathrm{C}$ observada por Buckley (1940).

A migração tardia das $\mathrm{L}_{3}$ das fezes para a gramínea no período seco, demonstrou que a chuva é utilizada como veículo de transmissão das $\mathrm{L}_{3}$ para a gramínea, que necessitam de uma película mínima de umidade para migrarem (LANGROVÁ et al., 2003).

Condiçôes climáticas como chuva e temperatura influenciam diretamente a sobrevivência e recuperação de larvas. A média de recuperação de $\mathrm{L}_{3}$ inferior no período chuvoso, provavelmente, deve-se ao aumento da precipitaçáo pluvial que dispersou as $\mathrm{L}_{3}$ na pastagem. A chuva, como fator limitante para a dispersáo de larvas de nematóides estrongilídeos de equinos na pastagem, foi descrito por English (1979 a, b), Ogbourne (1972, 1973) e Hutchinson, Abba e Mfitlodze (1989). A correlação moderada entre a presença de umidade e o número de larvas presentes na pastagem foi sugerida por Langrová et al. (2003), destacando que até o momento não se conhece bem como a temperatura influencia a migração das larvas.
Dependendo do tipo de gramínea, essa pode favorecer ou limitar a migração das $\mathrm{L}_{3}$. Na gramínea coast cross, o caule quase sem pelos, a pequena relaçáo colmo/folha, as folhas finas, pilosas e com pelos longos na base, observou-se menor recuperação de $\mathrm{L}_{3}$ quando comparado, com a gramínea tifton 85 (BEZERRA et al., 2007).

Maior número de $\mathrm{L}_{3}$ foi recuperado às 17 , não foi observada diferença significativa entre horários, esses resultados contrastam com uma maior recuperação de $\mathrm{L}_{3}$ no horário de 8 horas no estudo realizado por Langrová et al. (2003). As condiçôes climáticas variam a cada ano nas diversas partes do Mundo, o que pode justificar resultados diferentes para cada estudo.

\section{Conclusão}

As fezes funcionam como potencial reservatório de larvas infectantes de ciatostomíneos, acarretando um aumento da sobrevivência das larvas, principalmente no período seco, aumentando dessa forma o risco de infecção dos equinos.

A chuva funciona como veículo de dispersáo das $\mathrm{L}_{3}$ para a gramínea.

Todos os horários de coleta apresentaram potencial recuperação de larvas infectantes para os equinos.

\section{Referências}

ANJOS, D. H. S.; RODRIGUES, M. L. A. Diversity of the infracommunities of strongylid nematodes in the ventral colon of Equus caballus from Rio de Janeiro state, Brazil. Veterinary Parasitology, v. 136, n. 3-4, p. 251-257, 2006.

ANJOS, D. H. S.; RODRIGUES, M. L. A. Structure of the community of the Strongylidae nematodes in the dorsal colon of Equus caballus from Rio de Janeiro State - Brazil. Veterinary Parasitology, v. 112, n. 1-2, p. 109-116, 2003.

AYRES, M. et al. BioEstat 4.0: aplicações estatísticas nas áreas das ciências biológicas e médicas. 4 ed. Belém: IOEPA, 2005. 324 p.

BAUDENA, M. A. et al. Seasonal development and survival of equine cyathostome larvae on pasture in south Louisiana. Veterinary Parasitology, v. 88, n. 1-2, p. 51-60, 2000a.

BAUDENA, M. A. et al. Efficacy of the namatophagus fungus Duddingtonia flagrans in reducing equine cyathostome larvae on pasture in south Luisiana. Veterinary Parasitology, v. 89, n. 4, p. 219-230, 2000b.

BEVILAQUA, C. M. L.; RODRIGUES, M. L. A.; CONCORDET, D. Identification on infective larvae of some common strongyles of horses. Revue de Medicine Veterinaire, v. 44, n. 12, p. 989-995, 1993.

BEZERRA, S. Q. et al. Ciatostomíneos (Strongylidae - Cyathostominae) parasitas de cavalos: ecologia experimental dos estágios pré-parasíticos em gramínea tifton 85 (Cynodon spp. cv. tifton 85) na Baixada Fluminense, RJ, Brasil. Parasitologia Latinoamericana, v. 62, n. 1-2, p. 27-34, 2007.

BUCKLEY, J. J. C. Observations on the vertical migrations of infective larvae on certains bursate nematodes. Journal of Helminthology, v. 18, n. 2, p. 173-182, 1940.

CASTRO, A. A. et al. Potencial dos fungos nematófagos Arthrobotrys sp. e Monacrosporium thaumanisium para o controle de larvas de ciatostomíneos 
de equinos (Nematoda: Cyathostominae). Revista Brasileira de Parasitologia Veterinária, v. 12, n. 2, p. 53-55, 2003.

CORT, W. W. et al. Investigations on the control of hookworm disease. 2. The description of an apparatus for isolating infective hookworm larvae from soil. American Journal of Hygiene, v. 2, n. 1, p. 1-16, 1922.

COURTNEY, C. H. Seasonal transmission of equine cyathostomes in warm climates. Veterinary Parasitology, v. 85, n. 2-3, p. 173-180, 1999.

COURTNEY, C. H.; ASQUITH, R. L. Seasonal changes in pasture infectivity by equine cyathostomes in north central Florida. Equine Veterinary Journal, v. 17, n. 3, p. 240-242, 1985.

CRAIG, T. M.; BOWEN, J. M.; LUDWIG, K. G. Transmission of equine cyathostomes (Strongylidae) in central Texas. American Journal of Veteterinary Research, v. 44, n. 10, p. 1897-1896, 1983.

DUNCAN, J. L. Field studies on the epidemiology of mixed strongyle infection in the horse. Veterinary Record, v. 94, n. 15, p. 337-345, 1974.

ENGLISH, A. W. Epidemiology of equine strongylosis in Southern Queesland. 1.Bionomics of free-living stages in feces and on pasture. Australian Veterinary Journal, v. 55 n. 7, p. 299-305, 1979a.

ENGLISH, A. W. Epidemiology of equine strongylosis in Southern Queesland. 2. Survival and migration of infective larvae on herbage. Australian Veterinary Medicine, v. 55, n. 7, p. 306-309, 1979 b.

GORDON, H. M.; WHITLOCK, H. V. A new technique for counting nematode eggs in sheep faeces. Journal of Council for Scientific and Industrial Research in Australia, v. 12, n. 1, p. 50-52, 1939.

HERD, R. P. Pasture hygiene: a nonchemical approach to equine endoparasite control. Modern Veterinary Practice, v. 67, n. 1, p. 36-38, 1986.

HOUSTON, R. S.; FINCHER, G. T.; CRAIG, T. M. Vertical migration of infective larvae of equine strongyles in sand clay loam. American Journal of Veterinary Research, v. 45, n. 3, p. 575-577, 1984.

HUTCHINSON, G. W.; ABBA, S. A.; MFITLODZE, M. W. Seasonal translation of equine strongyle infective larvae to herbage in tropical Australia. Veterinary Parasitology, v. 33, n. 3-4, p. 251-263, 1989.

JUDEZ, A. L. Técnica de analisis de datos multidimensionales: bases teóricas y aplicaciones en agricultura. Madrid: Ministerio de Agricultura, Pesca y Alimentación; Centro de Publicaciones, D.L., 1989. 301 p.

KAPLAN, R. M. Anthelmintic resistance in nematodes of horses. Veterinary Research, v. 33, n. 5, p. 491-507, 2002.
LANGROVÁ, I. et al. Effect of climatic influences on the migrations of infective larvae of Cyathostominae. Veterinary Medicine - Czech, v. 48, n. 1-2, p. 18-24, 2003.

LARSEN, M. et al. Predatious activity of the nematode - trapping fungus Duddingtonia flagrans against cyatostome larvae in faeces after passage through the gastrointestinal tract of horses. Veterinary Parasitology, v. 60, n. 3-4, p. 315-320, 1995.

MATTHEWS, J. B. et al. Recent developments in research into the Cyathostominae and Anoplocephala perfoliata. Veterinary Research, v. 35, n. 4, p. 371-381, 2004.

OGBOURNE, C. P. Observations on the free-living stages of strongylid nematodes of the horses. Parasitology, v. 64, n. 3, p. 461-477, 1972.

OGBOURNE, C. P. Survival on herbage plots of infective larvae of strongylid nematodes of the horse. Journal of Helminthology, v. 47, n. 1, p. 9-16, 1973.

RAMSEY, Y. H. et al. Seasonal development of Cyathostominae larvae on pasture in a northern temperate region of the United Kingdom. Veterinary Parasitology, v. 119, n. 4, p. 307-318, 2004.

RÉDUA, C. R. O. et al. Avaliação da passagem do fungo nematófago Monacrosporium thaumasium pelo trato gastrintestinal de eqüinos. Ciência Animal, v. 12, n. 2, p. 133-139, 2002.

ROBERTS, H. S.; O'SULLIVAN, P. S. Methods for egg counts and larval cultures for Strongyles infesting the gastrointestinal tract of cattle. Australian Journal of Agriculture Research, v. 1, n. 1, p. 99-102, 1950.

RODRIGUES, M. L. A. Sobrevivência de ovos e larvas infectantes de nematóides (Nematoda, Strongylidae), intestinais de equinos, nas fezes e na pastagem. 1989. 98 f. Tese (Doutorado) - Universidade Federal Rural do Rio de Janeiro, Seropédica.

SAMPAIO, I. B. M. Estatística aplicada à experimentaçáo animal. 1 ed. Belo Horizonte: Fundaçáo de Ensino e Pesquisa em Medicina Veterinária e Zootecnia, 1998. 221 p.

STROMBERG, B. E. Environmental factors influencing transmission. Veterinary Parasitology, v. 72, n. 3-4, p. 247-264, 1997.

VIANA, L. P. Capacidade migratória de larvas infectantes de nematóides Strongylida parasitos de bovinos em diferentes espécies de forrageiras. 1999. 61 f. Dissertação (Mestrado) - Universidade Federal Rural do Rio de Janeiro, Seropédica.

ZAR, J. H. Biostatical analysis. 4 ed. Upper Saddle River: Prentice Hall, 1999. 663 p. 